\title{
Public health care system, a quasi-experimental study: Acceptance and attitude to implicate clinical services
}

\author{
SYED WASIF GILLANI ${ }^{1 *}$ \\ MOHI IQBAL MOHAMMAD ABDUL 2,3 \\ ${ }^{1}$ Department of Clinical $\mathcal{E}$ Hospital \\ Pharmacy, College of Pharmacy \\ Taibah University, Al Madinah Al \\ Munawarrah, Kingdom of Saudi Arabia \\ ${ }^{2}$ Department of Pharmacology \\ College of Pharmacy \\ Taibah University, Al Madinah Al \\ Munawarrah, Kingdom of Saudi Arabia \\ ${ }^{3}$ College of Pharmacy \\ University of Philippines, Manila \\ Philippines
}

\begin{abstract}
A six-month longitudinal intervention arm study with a prepost cross-sectional questionnaire-based survey was performed. A 3-phase objective structured clinical examination (OSCE) design was utilized for evaluation of acceptance and attitude of pharmacy students towards clinical pharmacy services. The pre-OSCE survey showed increased disagreement with the role of clinical pharmacists, compared to a significant positive shift in attitude towards their services in the healthcare team after 6 months of the trial. Responses improved for awareness (the current healthcare system could be improved by involving pharmacists, $p<0.02$ ) and positive attitude categories (doctors and nurses would be happy to welcome the services of competent clinical pharmacists as part of their team, $p<0.01$ ) in addition to competency (pharmacists have sufficient clinical training to advise doctors and nurses, $p<0.01$ ). The predictive model suggested a strong positive effect on patient interaction, medical information tasks, clinical decisions on drug-related problems (DRPs), and communication with healthcare professionals $\left(R^{2}=0.41, F=1.51, p<0.001\right)$.
\end{abstract}

Keywords: clinical pharmacy, pharmacy education, clinical training, objectively structured clinical examination

Non-communicable chronic diseases (NCCDs) are a potential global threat with significant health challenges for both developed and developing countries (1). Global NCCDrelated deaths are projected to increase by $15 \%$ between 2010 and 2020 with the greatest increases (> $20 \%$ ) estimated to be observed in Africa, the Eastern Mediterranean and South-East Asia (2). To date, cardiovascular diseases, diabetes, cancer, and chronic respiratory diseases account for the total NCCD-related deaths (1). Several countries have developed a multidisciplinary healthcare management system that includes pharmaceutical care services $(3,4)$. Better clinical outcomes and drug optimization/individualization management have been demonstrated with clinical pharmacy services in the healthcare management team (5).

\footnotetext{
*Correspondence; e-mail: wasifgillani@gmail.com
} 
In terms of the role of clinical pharmacists in the healthcare management team, the global research platform has shown numerous benefits of patient-oriented pharmaceutical care. These include significant reduction of negative outcomes of drug-related problems (DRPs) (6), improvement and monitoring of patient safety (7), rational use of medicines (4, $8,9)$ and reduction of treatment expenditure (10).

Current graduate pharmacy programs in Southeast Asian universities produce thousands of pharmacists every year. However, pharmacy graduates have limited clinical experience because of the didactic lecturing system. This limited clinical expertise might be due to limited on-campus resources (clinical laboratory), inadequate clinical pharmacy practice tutorials and a lack of clinical curriculum design. Other barriers may include resistance to changes in the current teaching model, lack of students' interest and lack of available, qualified and competent clinical pharmacists $(11,12)$.

A change in learning expectations is necessary to prepare students for the rapidly changing roles and responsibilities of the global community in the 21st century. The objectively structured clinical examination (OSCE) has been identified as a collaborative pedagogy that prepares pharmacy students for the new learning expectations (11). It begins with conceiving, identifying, assessing and implementing solutions, followed by ensuring the sustainability of the intervention for communities' needs. This active learning process helps pharmacy students develop critical and analytical thinking, problem-solving and team-work abilities, the use of information technology in medicine and the ability to take responsibility for one's own clinical decisions. However, there is a need for subjective assessment of pharmacy students' acceptance and awareness of the OSCE. This study is an evaluation of pharmacy students' attitudes and perceptions of the role and practices of clinical pharmacists in a healthcare management team.

\section{EXPERIMENTAL}

\section{Study design and procedures}

A six-month, longitudinal intervention arm study with a pre-post cross-sectional questionnaire-based survey was utilized to assess the attitude and perception of pharmacy students regarding the OSCE and the role of clinical pharmacy services.

Pharmacy students in their final year of graduate studies were included in the trial after obtaining a written informed consent from the elective course coordinator. All students were included in the 3-phase longitudinal arm OSCE design for clinical pharmacy practice. It was designed as follows: (i) medication reconciliation/data retrieval, (ii) evaluating drug related problems (DRPs), (iii) effective communication. A total of 60 graduate students were included in the OSCE trial program.

Post-graduate students were trained to act as simulated patients or healthcare professionals.

Phase I. Medication reconciliation/data retrieval. Station 01: Patient interaction/interview. Post-graduate students were trained to act as simulated patients with a detailed case history and relevant medication details. Each case involved specific tasks to be undertaken. Station 02: Form filling/data validation. - Graduate students were required to fill in medical 


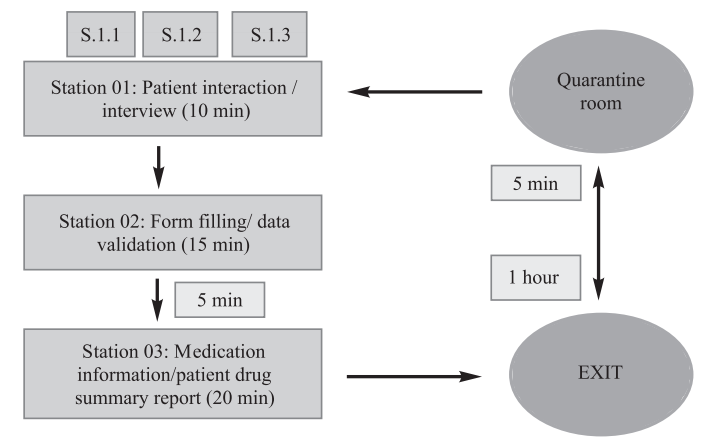

Fig. 1. Flow chart/plan for station 01: medication reconciliation/ data retrieval.

Quarantine area - participants' waiting area, station 01 - simulated patients, station 02 - medication reconciliation, station 03 - medicine information - reporting.

reconciliation forms or medication charts based on the information obtained in station 01 . They then had to evaluate the information and prepare a medication list form suitable for being presented to the doctor for assessment/diagnosis. Station 03: Medicine information/ patient drug summary report. - Students were required to evaluate the literature relevant to their particular case. Literature evaluation from reliable sources is a crucial part of a clinical evaluation and medication management plan (Fig. 1).

Phase II. Evaluating drug related problems (DRPs). Station 01: Identification of DRPs. - Postgraduate students were trained to act as simulated patients and were given detailed case histories and relevant medication details. Each case contained a clue leading to indication of a DRP. The students were required to identify the symptom/clue and declare if it was a "suspected" and/or "confirmed" DRP. Station 02: Assessment of DRPs. - Following the iden-

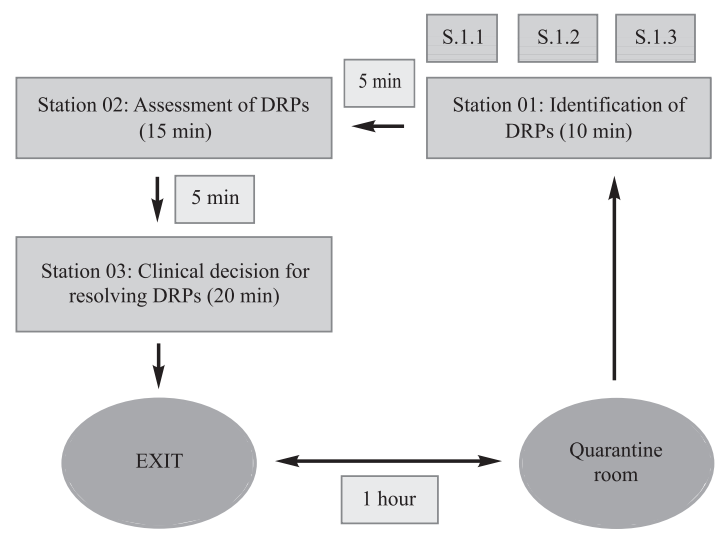

Fig. 2. Flow chart/plan for station 02: assessment of drug related problems (DRPs).

Quarantine area - participants waiting area, station 01 - identification of DRPs, station 02 - assessment tasks, station 03 - clinical resolution/recommendations. 
tification of DRPs, students were required to create an assessment report using reference textbooks or online search media. In the case of adverse drug reactions (ADRs), students were required to report them via pre-designed forms. Station 03: Clinical decision for resolving DRPs. - Students designed a pharmaceutical care plan for the relevant case. In addition, they were required to put notes on the pharmacotherapy forms for other healthcare providers (Fig. 2).

Phase III. Effective communication. Station 01: Problem introduction. - Clinical cases with identified DRPs and/or ADRs were provided to students. They were required to write key assessment points to communicate with both healthcare providers and patients. This was then followed by the development of follow-up protocols for the patients. Station 02: Communication with healthcare professionals. - Post-graduate students were trained to act as simulated healthcare professionals (nurse/doctor, depending on the case) with detailed case histories and relevant medication details. Students were required to communicate in an effective manner to transfer relevant information, attain feedback and discuss the followup protocol. Station 03: Communication with patients. - Post-graduate students were trained to act as simulated patients (inpatient/discharged, depending on the case) with detailed case histories and relevant medication details. The aim was to develop effective communication skills, provide relevant counselling points and attain patient affirmations. They were also required to discuss follow-up plans and provide various options to facilitate patient adherence (Fig. 3).

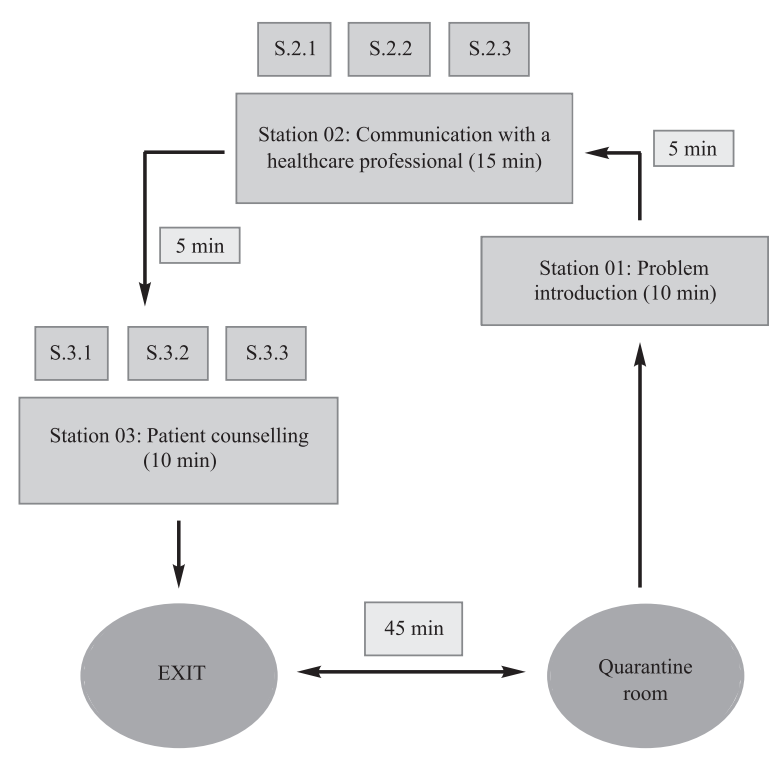

Fig. 3. Flow chart/plan for station 03: communication skills.

Quarantine area - participants waiting area, station 01 - case introduction, station 02 - communication skill tasks, station 03 - simulated patients' interactions/counselling tasks. 
S. W. Gillani and M. I. Mohammad Abdul: Public health care system, a quasi-experimental study: Acceptance and attitude to implicate clinical services, Acta Pharm. 67 (2017) 71-83.

Table I. Drug related problems in practice skill assessment cases during OSCE sessions ${ }^{a}$

\begin{tabular}{|c|c|c|c|c|c|c|}
\hline \multicolumn{2}{|c|}{ Subcategories of DRPs } & \multicolumn{2}{|c|}{ Identified $N(\%)$} & \multicolumn{2}{|c|}{ Resolved N (\%) } & \multirow{2}{*}{$p$-value } \\
\hline Hidden tasks & Total & Yes & No & Yes & No & \\
\hline Unnecessary therapy ${ }^{\mathrm{c}}$ & 10 & $47(78.3)$ & $13(21.7)$ & $45(75.0)$ & $15(25.0)$ & 0.71 \\
\hline Untreated indication $^{c}$ & 05 & $45(75.0)$ & $15(25.0)$ & $42(70.0)$ & $18(30.0)$ & 0.23 \\
\hline Inappropriate duration $^{c}$ & 07 & $40(66.7)$ & $20(33.3)$ & $49(81.7)$ & $11(18.3)$ & $0.02^{*}$ \\
\hline Inappropriate dose $\mathrm{c}^{\mathrm{c}}$ & 20 & $47(78.3)$ & $13(21.7)$ & $46(76.7)$ & $14(23.3)$ & 0.66 \\
\hline Drug-drug interactions ${ }^{b}$ & 15 & $42(70.0)$ & $18(30.0)$ & $40(66.7)$ & $20(33.3)$ & 0.42 \\
\hline Inadequate monitoring ${ }^{\mathrm{d}}$ & 10 & $37(61.7)$ & $23(38.3)$ & $36(60.0)$ & $24(40.0)$ & $0.01^{\#}$ \\
\hline Prescriber error ${ }^{\mathrm{b}}$ & 08 & $27(45.0)$ & $33(55.0)$ & $27(45.0)$ & $33(55.0)$ & 0.84 \\
\hline Manifest side effect ${ }^{\mathrm{d}}$ & 06 & $38(63.3)$ & $22(36.7)$ & $33(55.0)$ & $27(45.0)$ & $0.01^{\#}$ \\
\hline Duplication of therapy ${ }^{\mathrm{b}}$ & 10 & $51(85.0)$ & $9(15.0)$ & $50(83.3)$ & $10(16.7)$ & 0.85 \\
\hline Avoid contraindication $^{\mathrm{d}}$ & 20 & $21(35.0)$ & $39(65.0)$ & $18(30.0)$ & $42(70.0)$ & $0.01^{\#}$ \\
\hline Charting error $^{\mathrm{b}}$ & 04 & $17(28.3)$ & $43(71.7)$ & $12(20.0)$ & $48(80.0)$ & $0.01^{* *}$ \\
\hline
\end{tabular}

${ }^{a} N=60$ students.

Tasks for: ${ }^{\mathrm{b}}$ phase I, ${ }^{\mathrm{c}}$ phase II, ${ }^{\mathrm{d}}$ phase III.

Significant difference compared to resolved group: ${ }^{*} p<0.05,{ }^{* *} p<0.01$; identified group: ${ }^{\sharp} p<0.01$.

Task parameters and performance indicator. - Hidden DRPs in each task were classified according to the adapted Pharmaceutical Care Network Europe (PCNE) classification system V5.01 (13) (Table I). Performance indicator involved achieving $50 \%$ marks in each OSCE phase.

Cross-sectional questionnaire-based survey. - The views and general attitude of pharmacy students were assessed through a self-administered questionnaire. This questionnaire was developed and pre-tested in a pilot study and reviewed by a team of clinical pharmacists. The questionnaire sought the general attitude and perception of pharmacy students of the integrated medication management system of the patients and healthcare team. The answers were close-ended and limited to a 3-grade Likert scale, comprising "disagree," "neutral" or "agree" (Table II).

Other questions were customized to clinical pharmacy services provided by a healthcare management team (Table III). These questions were answered with dichotomized response alternatives "yes" or "no".

Participants and institutional consent. - The study was approved by the National Medical Research Registry (NMRR), Clinical Research Committee (CRC) and Institutional Research Board (IRB) of the Ministry of Health Malaysia and by the Taibah University Research Ethics Committee. Participants were informed about the purpose of the survey by the investigator. An individual consent form was attached to the questionnaire, which clearly explained the purpose of the survey and the right of participants to withhold their consent voluntarily. 
S. W. Gillani and M. I. Mohammad Abdul: Public health care system, a quasi-experimental study: Acceptance and attitude to implicate clinical services, Acta Pharm. 67 (2017) 71-83.

Table II. Attitude of pharmacy students to being a part of the healthcare team ${ }^{a}$

\begin{tabular}{|c|c|c|c|c|c|c|c|}
\hline \multirow{2}{*}{ Attribute } & \multicolumn{3}{|c|}{ Pre-OSCE survey $N(\%)$} & \multicolumn{3}{|c|}{ Post-OSCE survey $N(\%)$} & \multirow{2}{*}{$p$-value } \\
\hline & DA & $\mathrm{N}$ & A & DA & $\mathrm{N}$ & A & \\
\hline $\begin{array}{l}\text { Clinical pharmacist is a vital } \\
\text { element in healthcare team }\end{array}$ & $4(6.7)$ & $37(61.7)$ & 19 (31.6) & - & $9(15.0)$ & $51(85.0)$ & $0.01^{*}$ \\
\hline $\begin{array}{l}\text { Clinical pharmacist increases the } \\
\text { cost of care, thus unnecessary }\end{array}$ & $39(65.0)$ & $20(33.3)$ & $1(1.7)$ & 49 (81.7) & $11(18.3)$ & - & $0.01^{*}$ \\
\hline $\begin{array}{l}\text { Current healthcare system can be } \\
\text { improved by involving pharmacists }\end{array}$ & $17(28.3)$ & $3(5.0)$ & $40(66.7)$ & - & $5(8.3)$ & $55(91.7)$ & $0.02^{* *}$ \\
\hline $\begin{array}{l}\text { Doctor \& nurses would welcome } \\
\text { the services of a competent clinical } \\
\text { pharmacist as part of their team }\end{array}$ & $51(85.0)$ & $2(3.3)$ & $7(11.7)$ & $5(8.3)$ & $3(5.0)$ & $52(86.7)$ & $0.01^{*}$ \\
\hline $\begin{array}{l}\text { Patients often do not understand } \\
\text { medicines and errors occur in } \\
\text { hospitals }\end{array}$ & - & $17(28.3)$ & $43(71.7)$ & - & $5(8.3)$ & $55(91.7)$ & $0.03^{* *}$ \\
\hline $\begin{array}{l}\text { High prevalence of medication } \\
\text { errors but no surveillance for } \\
\text { preventing them }\end{array}$ & - & $21(35.0)$ & $39(65.0)$ & - & 19 (31.6) & $41(68.3)$ & 0.76 \\
\hline $\begin{array}{l}\text { Pharmacists have sufficient clinical } \\
\text { training to advice doctors \& nurses }\end{array}$ & $29(48.4)$ & 11 (18.3) & $20(33.3)$ & - & $4(6.7)$ & $56(93.3)$ & $0.01^{*}$ \\
\hline $\begin{array}{l}\text { Pharmacists play an important role } \\
\text { in drug individualization therapy } \\
\text { for patients }\end{array}$ & $33(55.0)$ & $16(26.7)$ & 11 (18.3) & - & $2(3.3)$ & $58(96.7)$ & $0.01^{*}$ \\
\hline $\begin{array}{l}\text { Pharmacists have specific training } \\
\text { in improving patient adherence }\end{array}$ & $10(16.7)$ & $16(26.7)$ & $34(56.6)$ & - & $12(20.0)$ & $48(80.0)$ & $0.01^{*}$ \\
\hline $\begin{array}{l}\text { Pharmacist is a vital bridge for } \\
\text { effective communication } \mathrm{b} / \mathrm{w} \text { health- } \\
\text { care team and patient efficacy }\end{array}$ & $47(78.3)$ & $10(16.7)$ & $3(5.0)$ & $7(11.7)$ & $15(25.0)$ & $38(63.3)$ & $0.01^{*}$ \\
\hline $\begin{array}{l}\text { Pharmacists can play an important } \\
\text { role in improving patient self-care } \\
\text { behaviour and related awareness }\end{array}$ & 19 (31.6) & $23(40.1)$ & $17(28.3)$ & $10(16.6)$ & $13(21.7)$ & $37(61.7)$ & 0.54 \\
\hline
\end{tabular}

DA - disagree, $\mathrm{N}$ - neutral, A - agree

${ }^{a} N=60$ students.

Significant difference compared to post-OSCE survey group: ${ }^{*} p<0.01,{ }^{* *} p<0.05$.

\section{Statistical analysis}

The data collected were analyzed using the IBM SPSS Statistics for Windows, Version 21.0 (IBM Corp., Armonk, NY, USA). A descriptive analysis was used to analyze the basic acceptance pattern. A hierarchical multiple regression analysis was performed for predictor variables to evaluate the $R^{2}$ change (functional change), F-test for change in $R^{2}$ (correlation) referred to as F-change, standardized beta coefficient (extent of the effect) to the out- 
S. W. Gillani and M. I. Mohammad Abdul: Public health care system, a quasi-experimental study: Acceptance and attitude to implicate clinical services, Acta Pharm. 67 (2017) 71-83.

Table III. Perception of pharmacy students of the role of clinical pharmacist-healthcare prospects ${ }^{a}$

\begin{tabular}{lccccc}
\hline & \multicolumn{2}{c}{ Pre-OSCE N (\%) } & \multicolumn{2}{c}{ Post-OSCE N (\%) } & p-value \\
\cline { 2 - 5 } Category & Yes & No & Yes & No & \\
\hline $\begin{array}{l}\text { Medication reconciliation for error } \\
\text { assessment }\end{array}$ & $21(35.0)$ & $39(65.0)$ & $60(100.0)$ & - & $0.01^{*}$ \\
$\begin{array}{l}\text { Alerting healthcare team on potential } \\
\text { and/or actual DRPs }\end{array}$ & $49(81.7)$ & $11(18.3)$ & $57(95.0)$ & $3(5.0)$ & $0.01^{*}$ \\
$\begin{array}{l}\text { Alerting prescriber on ADR-suspected as } \\
\text { well as existing }\end{array}$ & $41(68.3)$ & $19(31.7)$ & $59(98.3)$ & $1(1.7)$ & $0.02^{* *}$ \\
$\begin{array}{l}\text { Communicating and reporting } \\
\text { ADR-existing to relevant authorities }\end{array}$ & $58(96.7)$ & $02(3.3)$ & $60(100.0)$ & - & 0.74 \\
$\begin{array}{l}\text { Continuing professional development } \\
\text { organizer }\end{array}$ & $12(20.0)$ & $48(80.0)$ & $58(96.7)$ & $2(3.3)$ & $0.01^{*}$ \\
$\begin{array}{l}\text { Providing information to patients and } \\
\text { assisting in administration }\end{array}$ & $59(98.3)$ & $1(1.7)$ & $60(100.0)$ & - & 0.92 \\
$\begin{array}{l}\text { Ensuring all medications prescribed are } \\
\text { safe and appropriate for a patient }\end{array}$ & $29(48.3)$ & $31(51.7)$ & $60(100.0)$ & - & $0.01^{*}$ \\
$\begin{array}{l}\text { Assisting healthcare team in dosing } \\
\text { calculations (e.g., intravenous antibiotics, } \\
\text { intravenous infusions) }\end{array}$ & $39(65.0)$ & $21(35.0)$ & $59(98.3)$ & $1(1.7)$ & $0.02^{* *}$ \\
$\begin{array}{l}\text { Providing clinical feedback on drug } \\
\text { interactions to minimize errors }\end{array}$ & $23(38.3)$ & $37(61.7)$ & $60(100.0)$ & - & $0.01^{*}$ \\
\begin{tabular}{l} 
Avoiding unintentional errors in patients \\
\hline
\end{tabular} & $29(48.3)$ & $31(51.7)$ & $60(100.0)$ & - & $0.02^{* *}$ \\
\hline
\end{tabular}

${ }^{a} N=60$ students.

Significant difference compared to the post-OSCE survey group: ${ }^{*} p<0.01,{ }^{* *} p<0.05$.

come variable. The outcome variable is the perception change among participants during OSCE sessions. The covariance effect was considered effective with $p$-values less than 0.05 , which were considered to indicate statistical significance.

\section{RESULTS AND DISCUSSION}

A total of $75 \%(45 / 60,95 \%$ confidence interval, $70.1-79.3 \% ; p<0.001)$ of students accepted the presence of OSCE in the clinical curriculum along with achieving the required performance level. Further, $20 \%(12 / 60)$ of students accepted without fulfilling the performance indicator. However, $5 \%(3 / 60)(95 \%$ confidence interval $2.4-9.3 \% ; p<0.18)$ of students responded "no acceptance" of OSCE in clinical curriculum.

Pharmacy students were required to perform several hidden tasks. These clinical tasks were re-chartered under two categories: "identification" and "resolved". Pharmacy students showed significant positive output concerning "inappropriate duration" $(p<0.02)$ 
S. W. Gillani and M. I. Mohammad Abdul: Public health care system, a quasi-experimental study: Acceptance and attitude to implicate clinical services, Acta Pharm. 67 (2017) 71-83.

Table IV. Summary of hierarchical regression analysis for variables predicting perceptual change among OSCE participants ${ }^{a}$

\begin{tabular}{|c|c|c|c|c|c|c|c|c|c|c|c|c|}
\hline \multirow{2}{*}{ Variables } & \multicolumn{3}{|c|}{ Model 1} & \multicolumn{3}{|c|}{ Model 2} & \multicolumn{3}{|c|}{ Model 3} & \multicolumn{3}{|c|}{ Model 4} \\
\hline & B & SE & $\beta$ & B & SE & $\beta$ & B & SE & $\beta$ & B & SE & $\beta$ \\
\hline $\begin{array}{l}\text { Patient interaction/ } \\
\text { interview }\end{array}$ & 0.21 & 0.07 & $0.14^{c}$ & 0.23 & 0.09 & $0.15^{c}$ & 0.22 & 0.08 & $0.15^{\mathrm{b}}$ & 0.21 & 0.08 & $0.15^{c}$ \\
\hline Medication information & 0.75 & 0.60 & $0.19^{c}$ & 0.78 & 0.60 & $0.19^{c}$ & 0.75 & 0.07 & $0.19^{c}$ & 0.75 & 0.60 & $0.19^{c}$ \\
\hline Assessment of DRPs & -0.32 & 0.28 & $-0.22^{b}$ & -0.31 & 0.27 & $-0.22^{\mathrm{b}}$ & -0.29 & 0.27 & -0.20 & & & \\
\hline $\begin{array}{l}\text { Clinical decision on } \\
\text { DRPs }\end{array}$ & & & & 0.19 & 0.12 & $0.11^{\mathrm{b}}$ & 0.21 & 0.10 & $0.11^{\mathrm{b}}$ & 0.21 & 0.12 & $0.12^{\mathrm{b}}$ \\
\hline $\begin{array}{l}\text { Communication with } \\
\text { healthcare professionals }\end{array}$ & & & & & & & 0.83 & 0.59 & $0.23^{\mathrm{b}}$ & 0.81 & 0.40 & $0.21^{\mathrm{c}}$ \\
\hline $\begin{array}{l}\text { Follow-up counselling } \\
\text { of patients }\end{array}$ & & & & & & & -0.61 & -0.06 & $-0.32^{b}$ & & & \\
\hline$R^{2}$ & & 0.23 & & & 0.29 & & & 0.28 & & & 0.41 & \\
\hline$F$ for change in $R^{2}$ & & $4.21^{*}$ & & & $5.35^{*}$ & & & $2.24^{*}$ & & & $1.51^{* *}$ & \\
\hline
\end{tabular}

$B \& S E$ (unstandardized coefficients), $\beta$ (standardized coefficient), $R^{2}$ (coefficient of determination), $F$ for change in $R^{2}$ (ratio of two mean square values in regession)

${ }^{a} N=60$ students.

${ }^{*} p<0.05,{ }^{* *} p<0.01$

and negative variance with "inadequate monitoring" $(p<0.01)$, "prescriber errors" ( $p<$ $0.01)$, "avoid contraindication" ( $p<0.01)$ and "charting error" $(p<0.01)$ (Table I).

A total of eleven different types of hidden tasks were used for assessments of threephase OSCE (Table I). The assessment of phase I showed that $71.1 \%$ students failed to identify "charting errors". Also, correct solution was provided by only $20.0 \%$ participants, which was significantly lower than the number of participants who initially identified the errors $(p<0.01)$. However, there were non-significant differences in all the other tasks in this phase for identification and resolution patterns.

Drug related problem (DRP) assessment is one of the critical roles of clinical pharmacists to optimize patient care and improve the quality of care. Thus phase II reflects the anticipated participants' skills to practice. The results showed that all the tasks exhibited non-significant differences except the "inappropriate drug duration" tasks where only $18.3 \%$ participants managed to resolve the error, which was significantly $(p<0.02)$ lower than $33.3 \%$ of participants who initially identified the error. This finding reflects the lack of drug-dose and drug-duration knowledge. This knowledge can be improved by multiple practice OSCE sessions and drug-dose and/or duration focused tutorials.

Phase III assessment results showed that "inadequate monitoring" tasks had a 60:40 response ratio among graduate students; nearly half of the participants were unable to complete the task correctly. A similar pattern was found for "manifest side effects" with a 55:45 response ratio. However, a large number of graduate students (70 \% approx.) were 
S. W. Gillani and M. I. Mohammad Abdul: Public health care system, a quasi-experimental study: Acceptance and attitude to implicate clinical services, Acta Pharm. 67 (2017) 71-83.

unable to either identify or resolve "avoid contraindication" tasks. Findings suggest an intense need for pharmaceutical care curriculum reform. It is usually suggested to include inferential learning to reboot students' understanding and knowledge.

A questionnaire-based survey was employed at pre- and post-OSCE sessions to evaluate the impact of sessions on students' attitudes and perceptions. Findings of the survey are summarized in Tables II and III. Findings of the attitude part revealed a high degree of disagreement with the role of the clinical pharmacist as a healthcare practitioner. However, the post-OSCE survey findings showed a significant positive shift in the attitude towards the clinical pharmacist's services within the healthcare team. Categories to which responses were improved were: the current healthcare system could be improved by involving pharmacists, $p<0.02$, doctors and nurses would be happy to welcome the services of a competent clinical pharmacists as part of their team, $p<0.01$, and pharmacists have sufficient clinical training to advise doctors and nurses, $p<0.01$. Also, improvement in the response to skill adequacy (pharmacists are the vital bridge to effective communication between the healthcare team and patient, $p<0.01$ ) was observed (Table II). Findings presented in Table II also show that the majority (61.7\%) of students (pre-OSCE survey) gave a "neutral" response to "clinical pharmacist is a vital element in healthcare system" but responses in the post-OSCE survey were significantly $(p<0.01)$ higher towards "agree". This showed that positive attitudes of graduate students improved with OSCE sessions. To avoid bias, a negative option was included in the survey instrument (i.e., "clinical pharmacist increases the cost of care and is thus unnecessary"). However, only $65 \%$ of "disagree" in pre-OSCE increased significantly $(p<0.01)$ to $81.7 \%$ in post-OSCE. A similar significant $(p<0.03)$ increase in responses towards "agree" (from 71.1 to $91.7 \%$ ) in the post-OSCE survey was found for the statement "patients often do not understand medicines and errors occur in hospital" reflecting participants improved knowledge and awareness. This indicated that OSCE sessions had improved graduate students' knowledge, understanding, skills, attitudes to and awareness of clinical practices.

Table III summarizes the perception of pharmacy graduate students of the role of clinical pharmacists in the healthcare system. Graduate students showed significant positive covariance relating to medication reconciliation for error assessment, reporting DRPs, assessment of ADRs, continuous professional development (CPD), and providing clinical feedback on drug interactions. Discussion related to findings presented in Table III suggests improved clinical skills and perception of graduate students of the clinical practices and role of clinical pharmacists in the healthcare system. The findings showed a significant difference in response "yes" $(p<0.01)$ to "medication reconciliation" as a necessary part for error assessment process from $35.0 \%$ students (pre-OSCE survey) to all $100.0 \%$ students (post-OSCE survey). Response "yes" to "alerting healthcare team on potential and/or actual ADR" improved significantly $(p<0.01)$ from 81.7 to $95.0 \%$. A similar shift of positive response to "alerting prescriber on ADR-suspected as well as existing" changed from 68.3 to $98.3 \%$ in the post-OSCE survey, i.e., it was significantly $(p<0.02)$ higher than in the pre-OSCE survey. These improved responses show a positive influence of OSCE sessions on graduate students' level of participation in the early patient care process. Other positive influence seen in the response to "continuous professional development organizer" (pre-OSCE $20.0 \%$ : $96.7 \%$ post-OSCE) improved significantly $(p<0.01)$, "ensuring all medication prescribed are safe and appropriate for a patient" (pre-OSCE $48.3 \%$ : $100.0 \%$ post-OSCE) improved significantly $(p<0.01)$, "assisting healthcare team in dosing calculations" (pre-OSCE $65.0 \%: 98.3 \%$ post-OSCE) improved significantly $(p<0.02)$, etc. 
S. W. Gillani and M. I. Mohammad Abdul: Public health care system, a quasi-experimental study: Acceptance and attitude to implicate clinical services, Acta Pharm. 67 (2017) 71-83.

(Table III). These findings clearly reflect the development of professionalism, sense of responsibility and team working skills of graduate students during OSCE sessions.

A "hierarchical regression" analysis was used to predict the factors affecting the perceptual change of graduate students during OSCE sessions (Table IV). A total of six variables were identified as having a significant association with the students' perceptual change. Regression modelling was performed to estimate the impact and extent of association to predict the dependable variable. Four different models were designed to predict the response with the fewest response variations in the fitted-plot graph.

In the discussion on the data presented in Table IV, models were evaluated for $R^{2}$ values (coefficient of determination suggesting goodness of fit) and $F$ for change in $R^{2}$ (suggesting that variables added improved the prediction). A significant $F$-change means that the variables added to the step/model significantly improved the prediction and the low $F$-change value (1.51) showed the fewest response variations among variables.

Both standardized and non-standardized beta coefficients were also tested for significance, thus predicting the linearity/correlation pattern among exposure variables to the final outcome variable (perceptual change during OSCE-sessions). Beta coefficient can be a positive or a negative value and the significance of that value is associated with it. If the beta coefficient is not statistically significant, then no significance can be interpreted from this predictor. Also, if the beta coefficient is positive, it means that for every 1-unit increase in the predictor variable the dependent variable will increase by the unstandardized beta coefficient value. However, if the $F$ change of $R^{2}$ is statistically significant (typically $p<$ 0.05), this signifies that the model (predictors) improved prediction of the outcome variable (perceptual change) and that there is a significant relationship between the set of predictors and the dependent variable.

In model 1, only three variables were used to estimate the prediction. Two of them showed positive $\beta(0.14 \& 0.19)$ suggesting a significant $(p<0.01)$ "perceptual change during OSCE sessions". However, "assessment of DRPs" contributed a negative $(-0.32 B$ with $\beta-0.22, p<0.05)$ impact on predicting the outcome variable. However, model 1 suggests only $23 \% R^{2}$ accountable change to perceptual change in OSCE sessions. The $F$ for change in $R^{2}$ of 4.21 suggested unexpectedly high variation among groups. Model 2 integrated four variables. Analysis suggests $29 \% R^{2}$ accountable change with $F$ of $5.35(p<0.01)$, which indicated high variation among the predictor variables. Further modelling is, however, needed to minimize intervariable variations and increase the functional $R^{2}$ value. In model 3, all the six variables were added to complete the prediction. This model predicts the $R^{2}$ change with $28 \%$ only; however, intervariable variations were significantly reduced to $2.24(p<0.05)$. However, analysis showed that two variables exhibited a negative standardized $\beta$ coefficient.All the variables were added to model 4 except "assessment of DRPs" and "follow-up counselling patients" (exhibited a negative impact on predicting perceptual change of graduate students). The $R^{2}$ increased to $41 \%, F$ for change in $R^{2}(1.51)$ significantly $(p<0.01)$ improved the prediction Thus model 4 (predictor variables) showed a significant relationship between clinical variables and perceptual change during OSCE sessions.

Pharmacy curricula must be designed in a way that provides education and training with a capacity to build therapeutic knowledge, clinical skills and a positive attitude to the practice of pharmaceutical care. To the best of our knowledge, this is the first study evaluating the acceptance, attitude and impact of OSCE on pharmacy students as a healthcare team. The findings showed that the inclusion of OSCEs in the current pharmacy clinical 
curriculum resulted in a high acceptance rate, with students showing $80 \%$ improved positive covariance in the attitude components. These findings provide sufficient useful information to help in developing pharmacy students' interest in learning and development. This can be facilitated by OSCEs that enhance the students' training and skills to better serve the needs of patients and the community (14-16).

The results show that students possessed sufficient skills to assess practice cases during the OSCE sessions. These cases contained hidden DRPs, which is a key element in the development of a pharmaceutical care plan. The students' ability to deal with the two main components, identification and solution, of the respective DRP task was tested. This suggests that the current pharmacy curriculum encourages the development of clinical pharmacists, who are motivated to incorporate the concept of pharmaceutical care into their professional practice. This finding is consistent with other studies conducted in the United States of America (17), Saudi Arabia (18), Nigeria (19), Kuwait (20) and Pakistan (21), in which pharmacy students were found to be well exposed to the clinical and healthcare settings. Another study reported that the pharmacy curriculum must provide students with adequate clinical knowledge, skills, and a set of values and attitudes that support the assumption of enhanced practice and responsibilities of performing pharmaceutical care in a patient and/or community setting (22). That study reported a significant level of improvement in students' attitudes towards healthcare practice and teams. Hence, this professional attitude can be attained using OSCE sessions.

To enhance the students' performance regarding the practice of pharmaceutical care, the identification of factors that are associated with pharmacy students' positive perception of the role of the clinical pharmacist is important. The present study utilized a prepost self-administered questionnaire-based survey to evaluate students' perceptions of the role of the clinical pharmacist in the healthcare management team. Overall, students' perceptions showed a negative trend at the pre-OSCE assessment; however, there was a significant improvement among all attributes after 6 months of the OSCE trial. We believe that the OSCE experience furnished additional benefits, including providing students with better and greater understanding of the clinical pharmacy practice $(23,24)$.

Due to the 6-month duration of the OSCE experience, the model was limited in its ability to assess the influence of long durations of OSCE experiences on students' attitudes towards pharmaceutical care and practice skills. However, through our model (Table IV) we were still able to suggest four predictive factors that influenced students' acceptance and performance during the OSCE sessions. These included evaluation of medication information and communication with healthcare professionals. The significant values show a positive/negative correlation pattern between predictor variables and the outcome variable (perceptual change).

Data in this study suggest that pharmacy students have shown enhanced attitudes and perception through the experience of OSCE trials in the clinical pharmacy practice. This could improve their professional development and future professional practice. Multivariate regression analysis was able to predict factors influencing students' learning interests and relative acceptance of OSCEs in the clinical pharmacy curricula.

\section{Study limitations}

(i) One of the major study limitations was the small number of participants $(N=60$ graduate students). 
(ii) The study was focused on pharmacy graduates only. A similar design study is needed to be expanded to the third and fourth year students of pharmacy, and also to other healthcare professional graduates.

(iii) The study was also limited by the student-staff ratio.

(iv) It is suggested to increase the assessment parameters for each station in all the three-phase OSCEs.

(v) Short-term research (only 6-month duration of the OSCE experience) model was limited in its ability to assess the influence of longer lasting OSCE experiences.

\section{CONCLUSIONS}

This study demonstrated the essential need for OSCEs in the clinical pharmacy curriculum for the pharmacy degree. Students showed exceptional improvement in attitude to and perception of services provided to the healthcare management team. Furthermore, OSCE was designed in a three-phase session covering all aspects of the patients. These include their history, assessment, evaluation, communication, approval, implementation, monitoring, care plan, discharge plan, counselling and follow-up.

The key points of the research could be summarized as follows: (i) acceptance and performance of pharmacy students at the OSCE designed examination, (ii) impact of OSCEs on students' clinical skills, (iii) impact of OSCEs on students' attitude towards services of clinical pharmacists, (iv) impact of OSCEs on students' perception of clinical pharmacists, $(v)$ determination of the degree and effect of acceptance of OSCEs with different task skills of OSCE design.

Future studies on other student populations (third and fourth year students of pharmacy and other healthcare professional graduates) with greater variation in the duration of the OSCE experience are needed to explore the effects of the duration of each OSCE station on students' attitudes and the relative impact on perception.

\section{REFERENCES}

1. A. Alwan, D. R. Maclean, L. M. Riley, E. T. d'Espaignet, C. D. Mathers, G. A. Stevens and D. Bettcher, Monitoring and surveillance of chronic noncommunicable diseases: progress and capacity in high-burden countries, Lancet 376 (2010) 1861-1868; DOI: 10.1016/S0140-6736(10)61853-3.

2. World Health Organization, The Global Burden of Disease: 2004 Update, WHO, Geneva 2008.

3. C. S. J. Ma, R. S. Holuby and L. L. Bucci, Physician and pharmacist collaboration: The University of Hawai'i at Hilo College of Pharmacy - JABSOM experience, Hawaii Med. J. 69 (2010) (No. 6, Suppl. 3) $42-44$.

4. A. Bergkvist, P. Midlöv, P. Höglund, L. Larsson and T. Eriksson, A multi-intervention approach on drug therapy can lead to a more appropriate drug use in the elderly. LIMM-Landskrona Integrated Medicines Management, J. Eval. Clin. Pract. 15 (2009) 660-667; DOI:10.1111/j.1365-2753.2008.01080.x.

5. A. H. Talasaz, The potential role of clinical pharmacy services in patients with cardiovascular diseases, J. Tehran Heart Cent. 7 (2012) 41-46.

6. C. Scullin, M. G. Scott, A. Hogg and J. C. McElnay, An innovative approach to integrated medicines management, J. Eval. Clin. Pract. 13 (2007) 781-788; DOI: 10.1111/j.1365-2753.2006.00753.x. 
7. P. J. Kaboli, A. B. Hoth, B. J. McClimon and J. L. Schnipper, Clinical pharmacists and inpatient medical care: a systematic review, Arch. Intern. Med.166(2006)955-964; DOI: 10.1001/archinte.166.9.955.

8. L. M. Hellström, Â. Bondesson, P. Höglund, P. Midlöv, L. Holmdahl, E. Rickhag and T. Eriksson, Impact of the Lund Integrated Medicines Management (LIMM) model on medication appropriateness and drug-related hospital revisits, Eur. J. Clin. Pharmacol. 67 (2011) 741-752; DOI: 10.1007/s00228010-0982-3.

9. A. Spinewine, C. Swine, S. Dhillon, P. Lambert, J. B. Nachega, L. Wilmotte and P. M. Tulkens, Effect of a collaborative approach on the quality of prescribing for geriatric inpatients: a randomized, controlled trial, J. Am. Geriatr. Soc. 55 (2007) 658-665; DOI: 10.1111/j.1532-5415.2007.01132.x.

10. U. Gillespie, A. Alassaad, D. Henrohn, H. Garmo, M. Hammarlund-Udenaes, H. Toss, A. KettisLindblad, H. Melhus and C. Morlin, A comprehensive pharmacist intervention to reduce morbidity in patients 80 years or older - A randomized controlled trial, Arch. Intern. Med. 169 (2009) 894-900; DOI: 10.1001/archinternmed.2009.71.

11. R. T. Calvert, Clinical pharmacy - a hospital perspective, Br. J. Clin. Pharmacol. 47 (1999) 231-238; DOI: 10.1046/j.1365-2125.1999.00845.x.

12. R. Baker, J. Camosso-Stefinovic, C. Gillies, E. J. Shaw, F. Cheater, S. Flottorp and N. Robertson, Tailored interventions to overcome identified barriers to change: effects on professional practice and health care outcomes, Cochrane Database Syst. 3 (2010), Article No. CD005470; DOI: 10.1002/14651858. CD005470.pub2.

13. Pharmaceutical Care Network Europe (PCNE), Classification for Drug-Related Problems V5.01; www. pcne.org/upload/files/16_PCNE_classification_V5.01.pdf;last access date September 15, 2016.

14. A. Bergkvist Christensen., L. Holmbjer, P. Midlöv, P. Höglund, L. Larsson, Â. Bondesson and T. Eriksson, The process of identifying, solving and preventing drug related problems in the LIMMstudy, Int. J. Clin. Pharm. 33 (2011) 1010-1018; DOI: 10.1007/s11096-011-9575-1.

15. C. Galindo, M. Olive, C. Lacasa, J. Martinez, C. Roure, M. Llado, I. Romero and A. Vila, Pharmaceutical care: pharmacy involvement in prescribing in an acute-care hospital, Pharm. World Sci. 25 (2003) 56-64.

16. G. Stemer and R. Lemmens-Gruber, The clinical pharmacist's contributions within the multidisciplinary patient care team of an intern nephrology ward, Int. J. Clin. Pharm. 33 (2011) 759-762.

17. B. C. Martin and M. A. Chishol,. Cross-validation of an instrument measuring students attitudes toward pharmaceutical care, Am. J. Pharm. Educ. 63 (1999) 46-51.

18 M. N. Al-Arifi, Pharmacy students' attitudes toward pharmaceutical care in Riyadh region Saudi Arabia, Pharm. World Sci. 31 (2009) 677-681; DOI: 10.1007/s11096-009-9331-y; DOI: 10.1007/s11096-0099331-y.

19. P. O. Udeogaranya, C. V. Ukwe and O. I. Ekwunife, Assessment of attitudes of University of Nigeria pharmacy students toward pharmaceutical care, Pharm. Pract. 7 (2009) 145-149; DOI: 10.4321/S188636552009000300003.

20. M. G. Katoue, A. I. Awad, T. L. Schwinghammer and S. B. Kombian, Pharmaceutical care education in Kuwait: pharmacy students' perspectives, Pharm. Pract. 12 (2014) 411-418.

21. N. Rahim and S. Nesar. Pharmacy undergraduate students' attitude toward pharmaceutical care in Pakistan, Int. J. Pharm. Pharm. Sci. 4 (2012) 113-116.

22. B. A. Adamick, Teaching pharmaceutical care: Removing the fences, Am. J. Pharm. Educ. 56 (1992) 434-441.

23. American Association of Colleges of Pharmacy (ACCP). Commission to Implement Change in Pharmaceutical Education, Background paper I: what is the mission of pharmaceutical education? Am. J. Pharm. Educ. 57 (1993) 374-376.

24. V. L. Culbertson, R. A. Larson and P. S. Cady, A conceptual frame-work for defining pharmaceutical diagnosis, Am. J. Pharm. Educ. 61 (1997) 12-18. 